\title{
A STUDY OF HISTOPATHOLOGICAL CHANGES IN THE GILL AND LIVER TISSUES OF FRESHWATER FISH HETEROPNEUSTES FOSSILIS EXPOSED TO CYPERMETHRIN TOXICITY
}

\author{
R. Nigar Sulthana \\ Department of Zoology \\ SPW Degree \& PG College, Tirupati
}

\section{Review Article}

Received: 02.03.2021

Accepted: 18.03.2021

Published: 23.03.2021

\begin{abstract}
The synthetic pyrethroid, cypermethrin toxicity was studied in fresh water fish 'Heteropneustes fossilis and the tissues like gill and liver were chosen for Histopathological effects by light microscopy, for 4 days and 7 days under sublethal concentrations. No Histopathological effects were observed in control group and 4 days group. Hence 7 days group was selected for the present study. Significant changes in Hepatic cells of liver were observed like cloudy swelling of hepatocytes, vacuolour degeneration, and dilation of sinusoids, Hepatic lesions, and Karyo Lexis. In Gill, oedema, Epithelial lining, curling of lamellae were observed. This study demonstrates the potential of electron microscopy in particular SEM, as a tool for detecting cypermethrin induced damage to liver and surface of gill lamellae.
\end{abstract}

Keywords: Organo phosphate Pesticide, Cypermethrin (CYP), Heteropneustes fossilis, Histopathology, Necrosis, Hypertrophy.

\section{INTRODUCTION}

Synthetic Pyrethroids considered to be an effective insecticides in Agriculture and Aquaculture due to their high insecticidal toxicity with low mammalian toxicity (Elliot et al., 1974) and easily biodegradable. These insecticides occur by ingestion of contaminated food uptake of waterborne residue and through the integument of observed material (Kerr \& vas (1973). The uptake of insecticide in fish was reported to be usually, mostly through the gills (Holden, 1962; Addison, 1976). Fish-specific organs such as the gills and their late metabolic action against this type of pesticide make fish highly susceptible to the toxicity of pyrethroid pesticides. Oxidative stress plays an important role in the neurological, reproductive and developmental toxicity caused by pyrethroids. Moreover, changes in antioxidant enzyme activity following pyrethroid pesticide exposure make fish more susceptible to oxidative stress caused by environmental pollutants. In this an attempt was made to examine occurrence of pyrethroid pesticides in the aquatic environment and oxidative stress induced toxicity in fish exposed to pyrethroids.

The synthetic pyrethroids were widely used in Agriculture, Animal Husbandry, post harvest technology is hazardous to the aquatic organisms. It also affects Environmental factors such as $\mathrm{P}^{\mathrm{H}}$, turbidity, alkalinity, dissolved Oxygen, temperature and conductivity. The lethal effect on aquatic organisms (Jayantha Rao, K. 1984) is in turn influenced by the rate of pollutants entering the water. Aquatic organisms, including fish are frequently exposed to a wide variety of environmental pollutants leading deleterious effects, especially when these contaminants are slightly

*Corresponding author: nigar2301@gmail.co 
decomposable, exhibit a high biological effectiveness and possess a high potential for accumulation or synergetic effects (Au., 2004). Fishes the most diverse group of vertebrate fauna are important component of the food chain and any effect of toxicant may have adverse influence on the nutritional value of fish and on human beings through their consumption.

Fishes are typical experimental models for toxicological investigations (Shiekh and Lee, 2008). They are often used to assess the biological impacts of contaminants and water quality because their response to low concentration of toxic substances (Ayas et al., 2007). In the present study, an attempt was made to examine the sublethal effects of different concentrations of Cypermethrin on the gills liver and muscle for 0 days, 4 days and 7 days.

\section{Wistopathological study:}

\section{a. Light Microscopy}

\section{Methodology}

The Heteropneustes fossilis, a freshwater fishes were procured from surrounding tanks of Kakinada, Andhra Pradesh and transferred to large $100 \mathrm{~L}$ glass aquaria $(120 X 45 X 80 \mathrm{~cm})$ containing dechlorinated tap water for acclimatization for a period of 20 days. They were fed daily with meat and liver of chicken. Afterwards the fish were exposed to according their biomass ratio (Donaldroff et al., 1951) to different concentrations of Cypermethrin.

The $\mathrm{LC}_{50}$ was determined (65 $\left.\mu \mathrm{g} / 1 / 48 \mathrm{~h}\right)$ tenfold lower concentration of the $\mathrm{LC}_{50}$ was selected as sublethal concentration $(0.52 \mu \mathrm{g} / \mathrm{L})$ and the fishes were exposed to 4 day and 7 days. Controls were maintained simultaneously without toxicants and analyses were done on zero day, $4^{\text {th }}$ day and $7^{\text {th }}$ day of experimentation. Tissues like liver and muscle were selected for Histopathological observations. Fishes were sacrificed and the tissues like Gill and liver were fixed in $10 \%$ neutral buffered formation. Gills alone were processed by double embedding technique. The fixed tissues were dehydrated in an increased gradient of alcohol (78, 80, 90 and $100 \%$ ) for 30 minutes each and were eventually dried in Acetone and cleared in Xylene for 30 minutes. The tissues were then infiltrated by embedding by embedding in molten wax and sectioned at $6 \mu$. The Paraffin sections were then mounted on slide, stained with Haematoxylin and counter stained with Eosin and were mounted in Canada balsom. Histopathological lesions were examined and photographed with the help of Intel Pentium QX3 computer attached microscope under $400 \mathrm{X}$ lens.

\section{RESULTS AND DISCUSSION}

Histology is useful technique for investigating the toxic effect of various pollutants. Such a study also offers opportunity to locate the effect of pollutants in various organs and systems of animals. This type of study in fish has to a great extent is handicapped because of inadequate histological literature concerning various fish organs (Hinton et al., 1977). Considerable interest has been shown in recent years in histopathological studies while conducting sub lethal test in fish. Tissue changes in test organisms exposed to sub lethal concentration of toxicants are a functional response of organisms which provides information on the nature of toxicants.

In fish, gill is the front organ to which any pollutant comes into contact. Fish gill is very sensitive to changes in the composition of the environment and is an important indicator of waterborne toxicants. Consequently, injury to gill epithelium is a common response observed in fish exposed to a variety of contaminants. The severity of damage to the gills depends on the concentration of the toxicant and the period of exposure.

The present histopathological observations of liver tissues showed degenerated hepato -pancreatic tissue, congested blood vessels, blood cells among hepatocytes BC, appearance of blood streaks among hepatocytes (ABS), vacuolar degeneration (VD), as well Necrosis and damage of hepatocytic cell wall and disposition of hepatic cords, (Aldora et al.1998) reported that after cypermethrin exposure, hepatocytes showed nuclear change and cytoplasmic vacuolation.

In Gill tissue histopathological alterations have showed remarkable changes in the structure. The changes include epithelial lining lifting (EL), bulging of tips of primary filaments (BTPG), degenerated secondary Lamella (DGSL), curling of secondary gill filamants (CSG), and atrophy of secondary lamella (ASL), fusion of secondary gill filaments (FSG). The damage of gills of fish exposed to the higher concentrations showed shortened and clubbing of ends of the secondary gill lamellae and necrosis in the primary lamella was well 
marked. Hyperplasia and Hypertrophy of nuclei were also noticed. The changes like Pyknotic Nuclei, Vacuolization and degeneration of epithelial cells and pillar cells and lifting of the epithelial layer from the secondary lamellae were also significant.

Liver is an important organ and plays fundamental role in the bio -transformation, in the uptake and detoxification of foreign composition (Gerrihofer et al., 2001) in the body and thus liver is a target organ of xenobiotics. It is also one of the most affected contaminants in water (Camargo and Martinez, 2007) and as a consequence it undergoes different levels of damage. Cypermethrin exposed fish liver showed degeneration in the hepatocytes, necrosis and aggression of inflammatory cells, dilation and congestion may be attributed to the direct toxic effects of pollutants, since the liver is the principle organ responsible for detoxification in vertebrates generally and in fish particularly. The liver during CYP exposed fish had vacuolated cells showing evidence of fatty degeneration. Vacuolations of hepatocytes is a common response associated with exposure of fish to a variety of toxic chemicals which might be an indication of imbalance the rate of synthesis of substances in the Parenchyma cells and the rate of their release into the circulation (Gngerich, 1982). cytoplasmic vacuolization observed in the liver tissue.
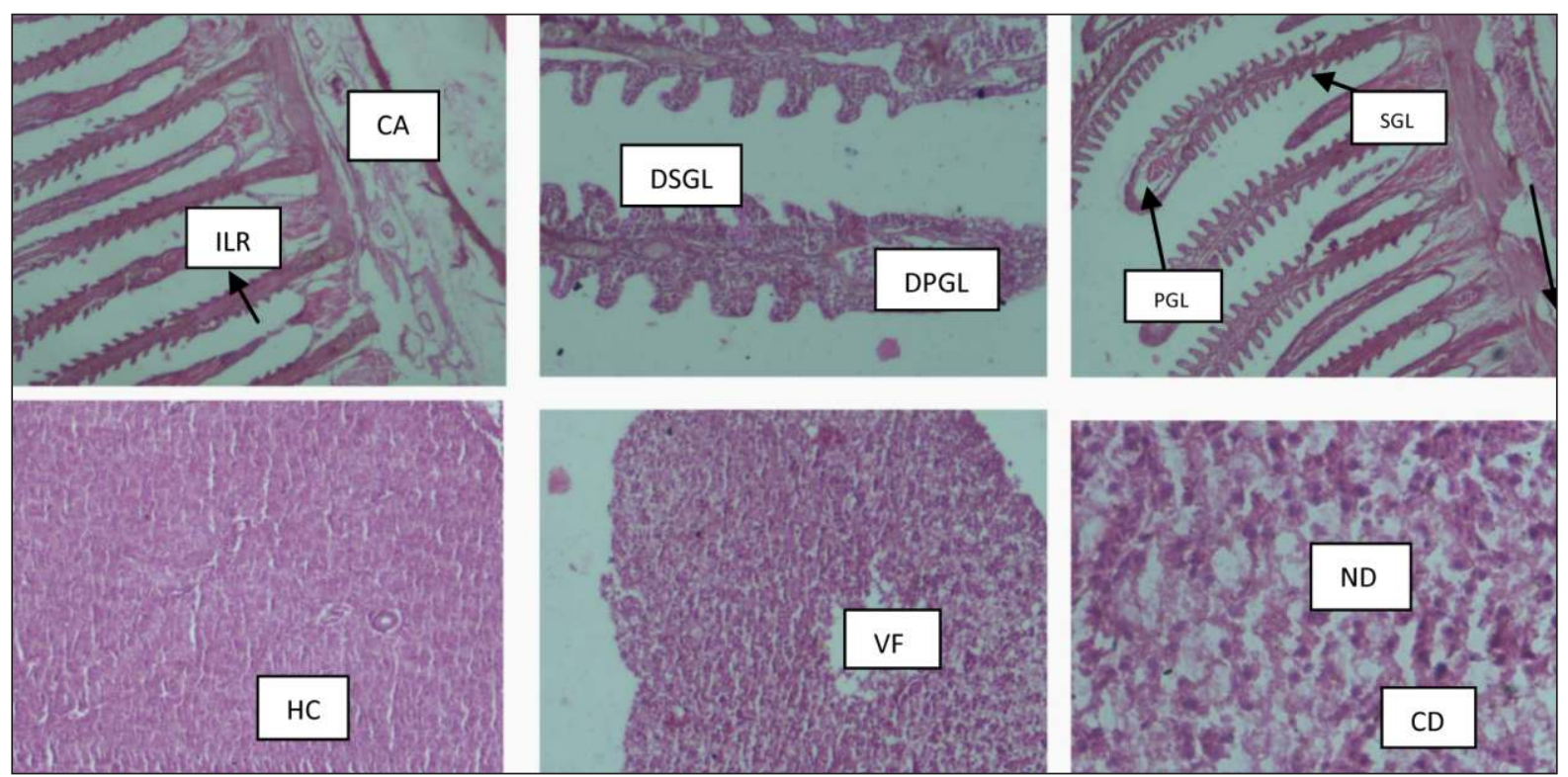

A-C CONTROL (Gill): PGL-primary gill Lamella, SGL-Secondary gill Lamella, CA-Central Axis, ILR-Inter Lamellar Region, Sublethal- B, DPGL-Degenerated Primary Gill Lamella, DSGL- Degenerated Secondary Gill Lamella Sublethal- C, LD-Lamellar Disorganization LF-Lamellar Fusion,

D-F CONTROL (Liver): N-Nucleus, GC-Granular Cytoplasm, HC- Hepatic Cell, E- NH, Nuclear Hypertrophy, BSbile Stagnation, VF- Vacuolar formation, EG- Eosinophilic Granules, ISN- Irregular Shaped Nucleus, F- NDNuclear Degeneration, CD- Cytoplasmic Degeneration, VF- Vacuole Formation.

A-C CONTROL (Gill): PGL-primary gill Lamella, SGL-Secondary gill Lamella, CA-Central Axis, ILRInter Lamellar Region, Sublethal- B, DPGLDegenerated Primary Gill Lamella, DSGLDegenerated Secondary Gill Lamella Sublethal- C, LD-Lamellar Disorganization LF-Lamellar Fusion, D-F CONTROL (Liver): N-Nucleus, GC-Granular Cytoplasm, HC- Hepatic Cell, E- NH, Nuclear Hypertrophy, BS-bile Stagnation, VF- Vacuolar formation, EG- Eosinophilic Granules, ISN- Irregular Shaped Nucleus, F- ND-Nuclear Degeneration, CDCytoplasmic Degeneration, VF- Vacuole Formation.

\section{ACKNOWLEDGEMENT}

The author is grateful to University Grants Commission (SERO-HYD) for sanctioning Minor Research Project (MRP-7095-16, Dt: 14-9-2018) to carry out the research project. 


\section{REFERENCES}

1. Au., D.W.T. 2004, The application of histocytopathological biomarkers in marine pollution monitoring: a review, Mar. Poll. Bull. 48:817-834.

2. Boran, H., Capkin, E., Altinok, I, and Terzi, E, 2012. Assessment of acute toxicity and histopathology of the fungicide captan in rainbow trout. Exp, Toxical, Pathol. 64(3); 175-179.

3. Camargo, M,M, and Martinwz, C. 2007, Histopathology of gills, Kidney and liver of a Neotropical fish caged in an urban stream. Neotrop. Ichthol. 5; 327-336.

4. Cengiz, E,I. 2006, Gill and kidney histopathology in the freshwater fish cyprinus carpio after acute exposure to deltamethrin. Environ. Toxicol. Pharmacol. 22: 200-204.

5. Das, B.K. and Mukherjee, S.C. 2000. A histopathological study of carp (Labeo rohita) exposed to Hexachlorocyclohexane. Veter. Arhi. 70(4): 169-180.

6. Fernandes, M.N. and Mazon, A.F. 2003. Environmental pollution and fish gill morphology. In: Val, A.L. and Kapoor, B.G. Eds., Fish adaptation, Science Publisher, Enfield, 203-231.

7. Gingerich, W.H. 1982. Hepatic toxicology of fishes. In: Aquatic toxicology. (Eds,: L.J. Weber). H. Ranen Press, New york. Pp. 55-105.

8. Gupta, P. And Srivatsava, N. 2006. Effects of sub-lethal concentrations of zinc on histological changes and bioaccumulation of zinc by kidney of fish channa punctatu (Bloch), Environ. Biol. 27: 211-215.

9. Abidi, R. (1986). Studi es on the toxicity of certain pesticides on fishes. Ph.D., Thesis, Allahabad University, Allahabad, India.

10. Aldridge, W.N. (1981). Organophosphorous compounds molecular basis for the biological properties. Sci. Prog. Oxf.,67; 131-147.

11. Arasta Tazeen Bias, V and S. Thakur Preeti (1996). Effect of nuvan on some biochemical parameters of Indian Catfish, Mystus vittatus, Journal of Environmental Biology, 17(2): 167-169.

12. Bandy, L.W. (1972). The bioaccumulation and translocation of DDT in an old field Ecosystem. Ph.D. Thesis. Ohio State University, Columbus.

13. Benerjee, S and S. Bhattacharya (1994). Histopathology of kidney of chnna punctatus exposed to chronic nonlethal level of elsan, mercury and ammonia. Ecotoxicology and Environmental safety, 29:265-275.

14. Barah Sabita and Yadav, R.N.S (1994). Endosulfan induced metabolic alterations in the muscle of the fresh water fish, Heteropneustes fossilis (Bloch). Geobios, 21(4) 289-293.

15. Begum, G, (2004). Carbofuran insecticide induced biochemical alterations of liver and muscle tissues of the fish clarias batrachus (Linn) and recovery response. Aquatic Toxicology, 6666:83-92.

16. Brazinskii, L.P., F. Kamaroski, Y. PorokhonIska, E.M. Pischolka, K. Yu and A.P. Rudenko (1979). Experimental DDT toxicosis of fish. Ozenn, Rechn, Rybn, Khoz, 144: 86-92.

17. Calabrese, A, F.P. Thurberg, and E. Gould (1977). Effects of Cadmium, mercury and silver on marine animals. Mar.Fish.Rev., 39:5-11

18. Cengiz, E.I. (2006). Gill and kidney histopathology in the fresh water fish cyprinus carpus after acute exposure to deltamethrin. Environmental Toxicology Phar., 22(2)200-204.

19. Das, B.K and S.C. Mukherjee (2000). Chronic toxic effects of quinalphos on some biochemical parameters in Labeo rohita(Ham.). Toxicology Letters, 114(1-3):11-8.,

20. Dubale, M.S and P. Shah (1979). Histopathological lesions induced by malathion in the liver of Channa punctatus. Indian Journal of Experimental biology, 17 (7): 693-697.

21. El-Gendy, K.S., N.M. Aly, E. Rashwann and A.H, El-Sebae (1998). Biochemical targets affected by sublethal doses of cypermethrin. Toxicology Letters, 95:143.

22. Ghosh, T.K. (1989). Influence of cypermethrin on the oxidative metabolism of fish Labeo rohita. Proc. Indian Acad. B, 55: 155-120.

23. Hingorani, H. G., K. Madhududhana Rao and R. Ramachandra (1973). An attempt to study pollution and fish mortality in Hussainsagar reservoir in Hyderabad. Ind. Fish. Ass. Vol.3.

24. Jayantha Rao, K. (1984). Histopathology as a diagnostic tool in evaluation of toxicity. Manual of Environ, Toxicol. Selected Lectures and Methods, pp. 35-40. 
25. Jonsson, K.R. and N. Jayabalan (1993). Sublethal effects of endosulphan the histology and protein pattern of Cyprinus carpio gills, Journal of Applied Ichthylogy, 9(1): 49-56.

26. Kawashima, Y., H. Miyahara, Ko Zuka and C. Chira (1981). Tissue distribution of hexachloroprene in lactating cows. Bull. Environ. Contam. Toxicol., 26:242.

27. LI, G,C, and Y.C. Choa (1981). Study on the acute fish toxicities of commonly used Pesticides. Nat,Sci. Counc: 146-152.

28. Mandal, P.K. and A.K. Kulshresta (1980). Histopathological changes induced by the sublethal sumithion in Clarias batrachus (Linn). Indian Journal of Experimental Biology, 18:547552.
29. Nagaratnamma, R. (1982). Effect of organophosphate pesticide on the Physiology of freshwater fish, Cyprinus carpio. Ph.D. Thesis, Sri Venkateswara University, Tirupati, India.

30. Prasanth, M.S and M. David (2006). Changes in nitrogen metabolism of the freshwater fish. Cirrhinus mrigala following exposure to cypermethrin. J. Basic Clin. Physicol. Pharmacol., 17 (1): 63-70.

31. Sakr, S.A and S.M. Hanafy (2002)/ Histological alterations in the liver and kidneyof toads (bufo regularis) intoxicated with a pyrethroid insecticide. Journal of Biological Sciences, 2(4):208-211. 